\title{
Resource format preferences across the medical curriculum
}

\author{
Keith M. Pickett, MLIS \\ See end of article for author's affiliation.
}

DOI: http://dx.doi.org/10.3163/1536-5050.104.3.003

\begin{abstract}
Objective: This research study sought to determine the formats (print or electronic) of articles and book chapters most-preferred by first-year medical students, third-year medical students entering clinical clerkships, and incoming residents and to determine if these preferences change during the course of the medical curriculum. These trends will enable academic health sciences libraries to make appropriate collection development decisions to best cater to their user populations.
\end{abstract}

Methods: First-year medical students, third-year medical students, and incoming medical residents were asked to complete a paper survey from September 2014 to June 2015. The survey consisted of five multiple-choice questions, with two questions given space for optional short answers. Quantitative and qualitative responses were collected and calculated using Microsoft Excel.

Results: First-year students, third-year students, and incoming residents all preferred to read journal articles and book chapters in print, except in cases where the article or book chapter is under ten pages in length. Although print is preferred, demand for electronic articles and book chapters increases as students progress from undergraduate medical education into residency. The only category where a majority of incoming residents chose an electronic resource was which format they would give to a colleague, if the article or book chapter was critical to the care of an individual patient.

Conclusions: The preference for print resources is strong across the medical curriculum, although residents show an increased preference for electronic materials when compared to first- and thirdyear students. Academic health sciences libraries should take these preferences into account when making decisions regarding collection development.

Keywords: Library Surveys, Library Collection Development, Information Services, Questionnaires

It is no new development that academic health sciences libraries are offering more and more electronic resources, whether it is due to financial concerns, desire for more space, convenience, user demand, and so on. These resources do deliver: they are portable, sometimes offer multiple-user access, and can be cost-effective as bindery and storage costs are not an issue.

Electronic resources are often packaged in bundles, affording academic health sciences libraries the opportunity to provide a host of different

A supplemental appendix and supplemental Table 1, Figure 1, Figure 2, Figure 3, Figure 4, Figure 5, and Figure 6 are available with the online version of this journal. electronic books, journals, and other resources that they would not be able to otherwise. In addition, many librarians, faculty, and administrators assume that millennial and post-millennial medical students and residents (postgraduate trainees) are comfortable using and often prefer electronic resources. But what formats do current medical students and residents really prefer? Does their preference for print or electronic resources change during the course of the medical curriculum? Understanding differences in preference may help libraries better match user needs. This research study aims to answer these questions and provide data upon which to make prudent, effective collection development decisions to provide the resources that medical students and residents prefer. 


\section{METHODS}

To determine the preference of print versus electronic resources over time, a paper survey, titled "Resource Format Preferences across the Medical Curriculum," was developed in June 2014. The author secured letters of support from administration and key faculty, and the survey project was approved by the Tulane University Institutional Review Board in July 2014. The paper survey was distributed to three key cohort groups in the Tulane School of Medicine: first-year medical students (T1s) at the beginning of their first year of medical school, third-year medical students entering clinical clerkships (T3s), and incoming firstyear residents (medical graduates who have just started postgraduate training). The data from these surveys were analyzed and compared to determine preferences and trends from the first year of medical school through first year of residency.

The survey consisted of five multiple-choice questions, with questions 1 and 5 having additional space for optional short answers (Appendix, online only). Each question had three possible answers: "Print," "Electronic," and "No preference." Paper surveys were chosen instead of electronic surveys so that they could be distributed and collected quickly, unobtrusively, and without the need for outside technology. Participation was voluntary, and no personal identifying information was collected at any time. All three groups were given the same survey. The survey questions were:

1. In general, how do you prefer to read books? Why? 2. If both formats are freely available and access is not an issue, how would you prefer to read medical textbooks required in the curriculum?

3. If both formats are freely available and access is not an issue, how would you prefer to read articles and/or book chapters that are under ten (10) pages long? 4. If both formats are freely available and access is not an issue, how would you prefer to read articles and/or book chapters that are ten (10) pages or longer? 5. If you were giving a colleague an article or book chapter to read that is critical to the care of a particular patient, what format would you give him/her? Why?

T1 students were surveyed during their required one-hour library orientation session as part of the "Foundations in Medicine" course. This orientation was held in a computer lab in the Rudolph Matas Library of the Health Sciences. Surveys were distributed and collected at the beginning of the orientation sessions held on September 9, September 11, September 30, October 2, October 7, and October
9 of 2014. T3 students were surveyed during their clinical clerkship orientation on May 6, 2015. The paper surveys were added to each student's orientation packet and collected by the author during a break in the orientation. Incoming residents were surveyed during two orientation events on June 16 (new internal medicine residents) and June 24 (all other departments) of 2015. Matas Library staffs a table where new residents can register for library accounts and learn about available resources while their ID badges are created. New residents were asked to participate in the survey if they so desired.

Survey data from each group were tallied manually, using hash marks on a paper form, and then transferred to a Microsoft Excel spreadsheet. Qualitative short answer responses were first transcribed into Microsoft Word documents to allow manual sorting. The qualitative short answer responses were first sorted by question and answer given (print, electronic, or no preference), then handsorted into categories. The qualitative data were then transferred to Microsoft Excel for calculation.

\section{RESULTS}

The general preference for print books, book chapters, and journal articles decreased from the beginning of the first year of medical school into residency, while preference for electronic resources increased (Table 1, online only).

A majority of students and residents prefer to read (unspecified) books in print regardless of where they are in the curriculum (question 1), but preference for electronic books does increase over time (Table 1 and Figure 1, online only). Similar results were seen when the general topic of "books" was limited to medical textbooks required in the curriculum (Table 1 and Figure 2, online only). A majority of surveyed students and residents, regardless of their point in the medical curriculum, preferred print textbooks. As students progressed into residency, preference for electronic textbooks more than doubled and the proportion of respondents who did not indicate a format preference increased from about $7 \%$ to about $11 \%$.

The only media where preference of print versus electronic resources did not change significantly over time was articles and/or book chapters under ten pages long (Figure 3, online only). All three groups indicated that they would prefer an electronic article or book chapter if it were brief. 
In the case of journal articles and/or book chapters ten pages or longer in length, the trend follows those seen with both books in general and required textbooks. Print journal articles and book chapters are preferred (Table 1 and Figure 4, online only). Even though preference for print articles and book chapters is strong throughout the curriculum, preference for print articles or book chapters decreases and preference for electronic articles or book chapters increases over time.

The results of question 5- "If you were giving a colleague an article or book chapter to read that is critical to the care of a particular patient, which format would you give him/her?" - were of particular interest because the question not only took the respondents' personal preferences into account, but also required respondents to make assumptions about their colleagues' preferences and took the clinical environment into account. Responses actually flipped, from a majority giving print at T1 to a majority giving electronic at resident level (Table 1 and Figure 5, online only).

The trend of reduced preferences for print was also reflected in the percentage of respondents who chose "Print" for every question. At T1, about $16 \%$ of respondents selected "Print" for each question; at the resident level, only about 9\% selected "Print" exclusively (Figure 6, online only).

\section{DISCUSSION}

The collected data suggest two conclusions when comparing the $\mathrm{T} 1, \mathrm{~T} 3$, and incoming resident groups. First, demand for print materials is strong and remains strong throughout the medical curriculum. These data suggest that academic health sciences libraries should consider providing print copies of required textbooks, if possible, to cater to students' and incoming residents' desire for print resources.

Second, the preference for electronic resources increases as students progress from undergraduate medical courses into residency, so medical library resources may need to be tailored to student level.

All three groups preferred electronic versions of material under ten pages long. These results are understandable considering that eye strain and comfort were given as major factors in students' and residents' preference for print books over electronic copies. Brief articles and book chapters can be read quickly, before eye strain becomes a limiting factor.
The preference for giving a colleague an article (question 5) flipped from print at T1 to electronic at the resident level. Many of the qualitative short reasons that residents gave for giving their colleagues electronic resources included the word "easy" (whether it be ease of sending or access), indicating that in the clinical environment, convenience and speed are major factors in choosing a format. This is not surprising, considering that the average doctor-patient interaction is about ten minutes long and usually results in at least one clinical question that cannot be answered without consulting an outside resource [1]. Therefore, the resource to be considered must be quickly and easily accessible if it is to make an immediate impact upon a clinical decision. Thus, electronic articles and book chapters seem to be most preferred in a clinical setting as opposed to a classroom setting. On the other hand, those who would give a print copy often wrote in a comment that the recipient would be more likely to read and consider a print article or chapter than an electronic version.

The short written answers given for questions 1 and 5 were remarkably similar across the three groups. All groups cited print books as being easier to read and annotate. Respondents who preferred print resources also stated that print was more comfortable and reduced eye strain and headaches. Respondents who preferred electronic materials cited portability, ease of full-text searching, reduction of paper waste, and overall convenience as main factors. These results are to be expected, though, as they are typical reasons for preferring one format over another.

In spite of electronic resources becoming more and more pervasive in the classroom, clinic, and the world at large, it seems that the demand for print books and journals is here to stay in academic health sciences libraries. Even though medical students now have a seemingly endless array of digital tools to support their scholarship and practice, something magical still seems to happen when a print resource is held and read. Academic health sciences libraries need to continue to offer electronic resources, especially as demand for study space increases while many collection development budgets decrease, but still keep a core collection of print books and journals in order to best cater to the preferences of students and residents across the medical curriculum. The proportion of print versus electronic resources may best be tailored to the levels of the trainees. 
This study has several limitations. First, all the survey participants were in one primary location (Tulane University), so results are not generalizable. The time span of the study was brief. At the time of survey collection, the T1 students were only in the first couple of months of their medical education and might not represent students at even a short time further on. Finally, this was a snapshot study; any change in resource preference might not be linear and constant over time and might change at short intervals.

\section{ACKNOWLEDGMENTS}

Neville Prendergast, Maureen (Molly) Knapp, AHIP, Mary Holt, and Barbara Volo of the Rudolph Matas Library of the Health Sciences at Tulane University provided invaluable assistance and support with this project.

\section{REFERENCE}

1. Smith R. Strategies for coping with information overload. BMJ. 2010;341:c7126. DOI: http://dx.doi.org/10. 1136/bmj.c7126.

\section{AUTHOR'S AFFILIATION}

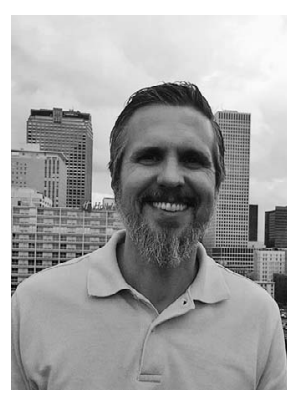

Keith M. Pickett, MLIS, kpicket1@tulane.edu, Research Support, Web Resources and Education Librarian, Rudolph Matas Library of the Health Sciences, Tulane University, 1430 Tulane Avenue, Mail Code 8586, New Orleans, LA 701122699

Received August 2015; accepted February 2016 